\title{
The therapeutic effects of earthworm extract on deep second- degree burn wound healing
}

\author{
Miao He ${ }^{1 \#}$, Wen-Qing Xie ${ }^{1 \#}$, Guo Cheng ${ }^{2}$, Wen-Ping Li ${ }^{2}$, Deng-Jie Yu ${ }^{1}$, Hong-Fu Jin ${ }^{1}$, Zhen-Han Deng ${ }^{1,3}$, \\ Yu-Sheng $\mathrm{Li}^{1,4}$ \\ ${ }^{1}$ Department of Orthopaedics, Xiangya Hospital, Central South University, Changsha, China; ${ }^{2}$ College of Veterinary Medicine, Hunan Agricultural \\ University, Changsha, China; ${ }^{3}$ Shenzhen Second People's Hospital/the First Affiliated Hospital of Shenzhen University Health Science Center, \\ Shenzhen, China; ${ }^{4}$ National Clinical Research Center for Geriatric Disorders, Xiangya Hospital, Central South University, Changsha, China \\ Contributions: (I) Conception and design: M He, YS Li, WQ Xie; (II) Administrative support: YS Li, ZH Deng; (III) Provision of study materials or \\ patients: YS Li, ZH Deng; (IV) Collection and assembly of data: WQ Xie, G Cheng, WP Li; (V) Data analysis and interpretation: M He, DJ Yu, HF \\ Jin; (VI) Manuscript writing: All authors; (VII) Final approval of manuscript: All authors. \\ \#These authors contributed equally to this work. \\ Correspondence to: Yu-Sheng Li. Department of Orthopaedics, Xiangya Hospital, Central South University, 87 Xiangya Road, Changsha 410008 , \\ Hunan, China. Email: liyusheng@csu.edu.cn; Zhen-Han Deng. Department of Sports Medicine, Shenzhen Second People’s Hospital/the First \\ Affiliated Hospital of Shenzhen University Health Science Center, Shenzhen, Guangdong, China. Email: dengzhenhan@email.szu.edu.cn.
}

Background To investigated the effect of earthworm extract (EE) on deep second-degree burn wound healing process.

Methods: A burn wound model was created on the mice's skin and was subject to different treatments: the control group received no treatment; the Jingwanhong (JWH: a well-established, widely used external ointment for treating burn wounds) group was treated with $0.1 \mathrm{~g}$ of JWH cream and spray it on the wound surface; the EE group was treated with $0.1 \mathrm{~mL}$ of EE solution. All the mice were sacrificed at 3, 7, 11, and 15 days after injury ( $\mathrm{n}=6$ /group/time point). Macroscopic observation, wound healing rate (WHR), wound healing time (WHT), water content (WC), hydroxyproline (Hyp) content, histological, and hematological analyses were performed at the burn wound sites.

Results: Better, faster burn wound healing in the JWH and EE groups than the control group at 15 days after injury were detected at the wound sites. Compared to the control group, the EE group had higher WHR, shorter WHT, lower WC, higher Hyp content, more fibroblasts, fibrocytes, and capillary endothelial cells; in addition, they showed greater capillary endothelial cell grouping at the wound sites during the healing process. This group also showed more platelets, white blood cells (WBCs), and neutrophilic granulocytes in serum at the early stages after burn injury.

Conclusions: EE could effectively promote skin wound healing by decreasing edema, suppressing fibrosis, activating angiogenesis and epithelial regeneration, inhibiting scar formation, and reducing the risk of infection. Thus, it could be made into a promising healing agent for burn wound.

Keywords: Earthworm extract (EE); deep second-degree burn; wound healing; Jingwanhong (JWH)

Submitted Dec 02, 2020. Accepted for publication Dec 17, 2020.

doi: 10.21037/apm-20-2393

View this article at: http://dx.doi.org/10.21037/apm-20-2393 


\section{Introduction}

The deep second-degree burn to the skin is a kind of burn marked by pain and anesthesia. This type of injury extends into the reticular dermis, compromising blood flow as well as destroying appendages. This type of burn usually takes more than a month to heal, and will mostly result in scarring (1). The injury will become more severe if not handled properly and tissue in the deeper layer underneath the wound may progress to destruction (2). The secondary damage of the tissue is related to changes in blood coagulation, fibrinolytic system, and other factors $(3,4)$. Therefore, there is a critical need for effective drugs to treat and/or cure second-degree burns.

Earthworm (Lumbrucis terrestris) is well known for its pharmaceutical value in Traditional Chinese Medicine. The written history of application of earthworms for medicinal usage can be traced back to $1578 \mathrm{AD}$, when ancient physician Shizhen Li detailed the medical uses of earthworms in The Compendium of Materia Medica $(5,6)$. The true effectiveness of many natural products still remain unproven because their components and underlying mechanisms aren't clearly described, which hampers new drug development (7). Thanks to modern technology, six types of proteolytic enzymes from the earthworm extract (EE) has been isolated; these active components of EE were jointly termed lumbrokinase or earthworm fibrinolytic enzyme (8). Lumbrokinase is able to inhibit intrinsic coagulation by dissolving fibrin and activating fibrinolysis by increasing tissue plasminogen activator activity (9). Encouragingly, it not only has anticoagulant and fibrinolytic properties, but also has anti-inflammatory $(10,11)$, antioxidant $(12,13)$, anti-apoptosis $(14,15)$, antimicrobial, anticancer (16) and other biological properties.

A previous study of ours found that EE could promote skin wound healing (17). However, the ability of EE to facilitate healing of more severe wounds, such as a deep second-degree burn, remains unknown. The purpose of this study is to investigate the influence of $\mathrm{EE}$ on the healing process of deep second-degree burn wound, and compare it with Jingwanhong (JWH), a well-established and widely used external ointment for treating burn wounds. In addition, it also explores the analgesic effects of $\mathrm{EE}$.

We present the following article in accordance with the ARRIVE reporting checklist (available at http://dx.doi. org/10.21037/apm-20-2393).

\section{Methods}

\section{Preparation of EE}

The procedure of EE preparation was the same as our previous study $(18,19)$. First of all, earthworm (Diehei II) and PBS $(0.02 \mathrm{~m}, \mathrm{pH} \leq 7.2)$ homogenates were centrifuged $\left(5,000 \times \mathrm{g}, 4^{\circ} \mathrm{C}, 10 \mathrm{~min}\right)$. Afterwards, the supernatant was collected. In the next step, the protein components were ultrafiltered through 100,50 , and $30 \mathrm{KD}$

Millipore ultrafilter $\left(5,000 \times \mathrm{g}, 4^{\circ} \mathrm{C}, 10 \mathrm{~min}\right)$. Researchers then collected the sediment and resuspended in PBS. After that, the solution was pulled into the $27 \mathrm{~mm}$ (MD34) dialysis bag (MW: 12,000-14,000) immersed in PBS. After undergoing dialysis and centrifugation $\left(5,000 \times \mathrm{g}, 4^{\circ} \mathrm{C}\right.$, 10 minutes), the final ultrafiltration solution (protein concentration: $2.56 \mathrm{mg} / \mathrm{mL}$ ) could be collected and preserved for further experimental use.

\section{Experimental animals}

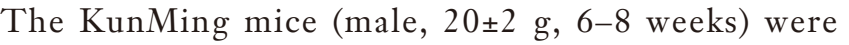
purchased from the animal Laboratory Animal Center of Central South University, China, and housed in the animal facility in Central South University. Experiments were performed under a project license (No.: 201907666) granted by the Ethics Committee of Xiangya Hospital, Central South University, in compliance with guidelines for the care and use of animals.

\section{Burn wound model}

A thermal injury procedure was introduced according to the method described previously (20). Briefly, the mice received a cocktail of ketamine hydrochloride $(50 \mathrm{mg} / \mathrm{kg}$ b.w.) and xylazine $(10 \mathrm{mg} / \mathrm{kg}$ b.w.) anesthesia intraperitoneally. Next, the dorsal fur was removed with an electronic hair clipper and hair removal cream. An even full-thickness $2 \mathrm{~cm}-$ diameter second-degree burn wound was induced by heated brass of $72{ }^{\circ} \mathrm{C}$ for 12 seconds on the exposed skin. Finally, the mice were kept in cages individually, and bupivacaine ( $2 \mathrm{mg} / \mathrm{kg}$ body weight) was subcutaneously injected for postoperative pain relief, and penicillin was used to prevent wound infection.

On the following day, 60 mice were randomly divided into three groups: EE treatment group, JWH group and control group. The burn wound of the EE treatment group 
mice was sprayed by $0.1 \mathrm{~mL}$ of EE, while $0.1 \mathrm{~g}$ of $\mathrm{JWH}$ cream was sprayed on the burn wound of JWH (Tianjin Darentang Jingwanhong Pharmaceutical Co., Ltd., China Tianjin, \# Z12040440). Meanwhile, the burn wounds in the control group were not treated. These wounds were treated twice a day until completely closed which means the wound area is generally equal to zero.

\section{Macroscopic observation}

The wound was photographed daily, and the researchers needed to monitor visually if the wound had edema, exudation, slice, erythema, and possible signs of infection. In addition, the researchers also needed to observe the wound's exudate, contraction, scabbing, color, and the dietary and mental state of experimental subjects at postoperative days (PODs) 3, 7, 15 following treatment.

\section{Wound healing rate (WHR) and wound healing time (WHT)}

The wound area after injury was calculated through tracking the edge of the wound and using an image analysis program (Image J, NIH, MD, USA) at POD 0, 3, 7, 11 and 15. Using these data, WHR was acquired by calculation formula as follows: $W H R=[($ Initial wound healing area $)$ - (wound healing area on day N)]/(initial wound healing area) $\times 100 \%$. Besides, researchers needed to record the date of the complete closure of the wound and the calculated WHT (day) accordingly.

\section{Histology}

The mice were sacrificed at POD 3, 7, 11 and 15 ( $n=6 /$ group/time point). The wounds were excised along with the surrounding skin. The specimens, a $2-\mathrm{mm}$ border of unwounded skin tissue were harvested and then fixed in $10 \%$ formalin, and embedded in paraffin. The tissue blocks were then equally divided into $5 \mu \mathrm{m}$ sections. The general morphology of the wound sites was revealed by Hematoxylin and eosin (HE). The slices were observed under a microscope for histological evaluation of the epidermis structure, epidermal-dermal junction, blisters, collagen bundles, epithelial regeneration, and granulocyte infiltration. The numbers of fibroblasts, fibrocytes, capillary endothelial cells and epithelial cells at the wound site were calculated for analysis at $100 \times$ field magnification using a microscope.

\section{Tissue water content (WC)}

Another set of mice were sacrificed at POD 3, 7, 11 and 15 ( $\mathrm{n}=6 /$ group/time point). $200 \mathrm{mg}$ of skin tissue at the wound site was collected. After absorbance of blood by filter paper, the wet weight $(\mathrm{WW})$ of the sample was determined. The dry weight (DW) of each sample was recorded after $24 \mathrm{~h}$ of baking in an $80{ }^{\circ} \mathrm{C}$ oven. The WC was acquired using the following formula: $\mathrm{WC}(\%)=(\mathrm{WW}-\mathrm{DW}) / \mathrm{DW} \times 100 \%$.

\section{Determination of hydroxyproline (Hyp)}

Skin tissue at the wound site was collected at POD 3 , 7, 11 and 15 ( $\mathrm{n}=6 /$ group/time point). The content of hydroxyproline in wound skin was determined by Hyp alkali hydrolysis kit (Nanjing Jiancheng Bioengineering Institute, Nanjing, China, batch \#20121023).

\section{Hematological analysis}

When the mice were sacrificed, whole blood specimens were collected (EDTA as in vitro anticoagulant) from the caudal vena cava at POD 3, 7, 11 and 15. Counting of platelets (PLTs), white blood cells (WBCs), and neutrophilic granulocyte (GRAN) from mice whole blood was performed using a hematology analyzer (sysmex, Japan).

\section{Statistical analysis}

All values are expressed as the mean \pm standard deviation (SD). All statistical analyses were performed using the SPSS 16.0 software (Chicago, IL, USA). The one-way analysis of variance (ANOVA), SNK-q, and Dunnett's T3 were applied respectively to determine multi-sample means comparisons and heterogeneity of variance. $\mathrm{P}<0.05$ was considered statistically significant.

\section{Results}

\section{Macroscopic observation}

No mice died of anesthesia, infection, or other complications during the entire experimental procedure. All mice were healthy without pathological reactions like shock, diarrhea, apastia, and so on. At POD 1, there were drowsiness and weakness in the control group mice, but the mice in the treatment groups were normal. Hemorrhage, edema, and exudation occurred around the burn wound area in all groups after modeling. 
The condition of wounds in each group was observed 3 days after treatment. Part of the scab began to slough away in EE group, indicating the rapid growth of granulation tissue. However, the other groups showed no evidence of scab sloughing. At POD 7, the EE group's wounds had been fully covered by new epidermal tissue, and neonatal hair began to grow on the surface of the healed skin. The scab began to slough away in JWH group. The newly emerged skin looked fresh and red in the control group. At POD 15 , neonatal hair fully covered the wound site in the EE treatment group. While the wound had still not completely healed in the other two groups, the JWH group showed better morphology than the control group (Figure 1).

\section{WHR and WHT}

A pair-wise comparison of WHR showed no difference between the three groups at POD $3(\mathrm{P}>0.05$, Table 1). On POD 7 and 11, the WHR in the JWH and EE groups were significantly higher compared to that of the control group, and the EE group had a higher WHR than the JWH group $(\mathrm{P}<0.01)$. Both the JWH and $\mathrm{EE}$ groups achieved complete healing at POD 15, the WHRs of which were significantly higher than that in control group $(\mathrm{P}<0.01)$.

The mean WHT in the three groups were $17.05 \pm 0.61$ (control group), $14.05 \pm 0.68$ (JWH group), $12.57 \pm 0.42$ (EE group). Both the EE and JWH group had shorter WHT than the control group $(\mathrm{P}<0.01)$, indicating a faster burn wound healing process in these two groups. In addition, WHT is significantly different between the EE group and the JWH group $(\mathrm{P}<0.05)$, indicating that $\mathrm{EE}$ can promote faster wound healing more effectively than JWH.

\section{Histology}

At POD 3, no signs of skin formation were showed in HE staining of each group. In the control group, we noticed that the substance among the wound cells was loose, the scar was closely attached to the dermal connective tissue with a large number of inflammatory cells infiltrating, and no new capillary formation or fibroblasts proliferation was found. However, there was a clear boundary between the scab and the dermis with a large number of inflammatory cells seen in the connective tissue in the JWH group. Compared with the JWH group, the EE group had more inflammatory cell infiltration with vasodilation but less intercellular substance, edema, new formation of capillaries, and proliferation of fibroblasts (Figure 2).

At POD 7, a large number of radial shaped fibroblasts appeared in the control group, most of whom were round or oval shaped and whose cytoplasm was lightly stained, and the intercellular substance was loose. In JWH group, the amount of inflammatory cells and formation of new capillaries decreased while fibroblasts diffused widely and arranged orderly. In EE group, there were fewer inflammatory cells and a large amount of asteroid or fusiform shaped fibroblasts emerged (large in size with many synapses). We also found that the nucleus were enlarged and oval shaped, stained deeply, arranged orderly, the number of capillaries increased and less granulation tissue formed.

At POD 11, the control group had showed that a thin layer of granulation tissue formed below the rough wound, which was composed of loose collagen fibers with small number of fibroblasts and small capillaries. In the JWH group, a layer of epithelial tissue formed covering the wound site. Furthermore, abundant connective tissue and radial fibroblasts gathered along with tightly arranged layers of collagenous fibers. In the EE group, it showed denser epithelial tissue and more proliferated granulation tissue. Also, it showed regular arrangement of mature dense collagen fibers and a large number of capillaries.

At POD 15, the control group showed coagulative necrosis, a tiny amount of granulation tissue, cells disorderly arranged, and few hair follicles and sebaceous glands. The wound site was fully covered by the new formed epidermis in the JWH and EE groups. Here, the dense epidermal cells were in good shape and orderly arranged. In the dermal tissue, the intercellular substance was filled with a large amount of collagen fibers. The subcutaneous tissue was filled with adipocytes and showed greater hair follicle formation. The morphology of newly formed cells and tissues was better in the $\mathrm{EE}$ group.

\section{Cell numbers at the wound site}

The EE could effectively increase the fibroblast, fibrocyte, capillary endothelial cell, and epithelial cell numbers at 11 days after burn wound (Table 2). The number of fibroblasts, fibrocytes, capillary endothelial cells, and epithelial cells in EE and JWH groups were significantly higher than those of the control group $(\mathrm{P}<0.01)$, and the numbers in the EE group were higher than those of the JWH group $(\mathrm{P}<0.01)$. 
Control
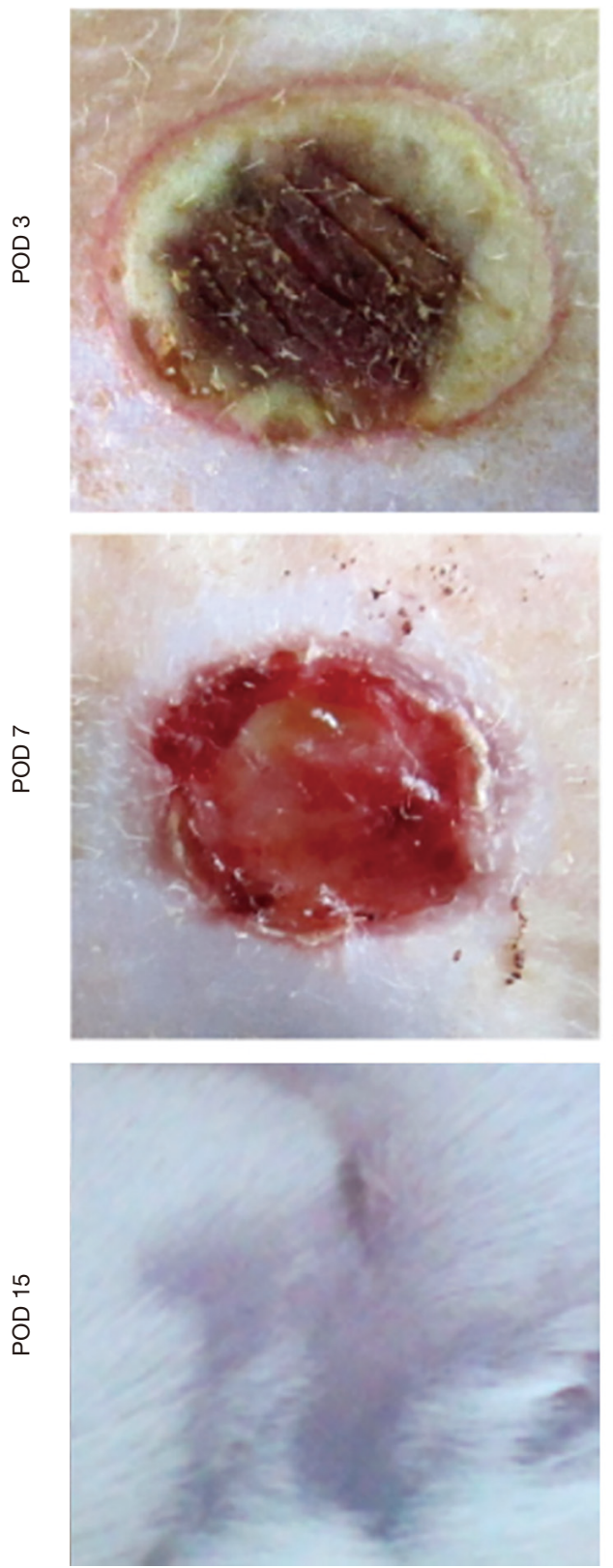

JWH
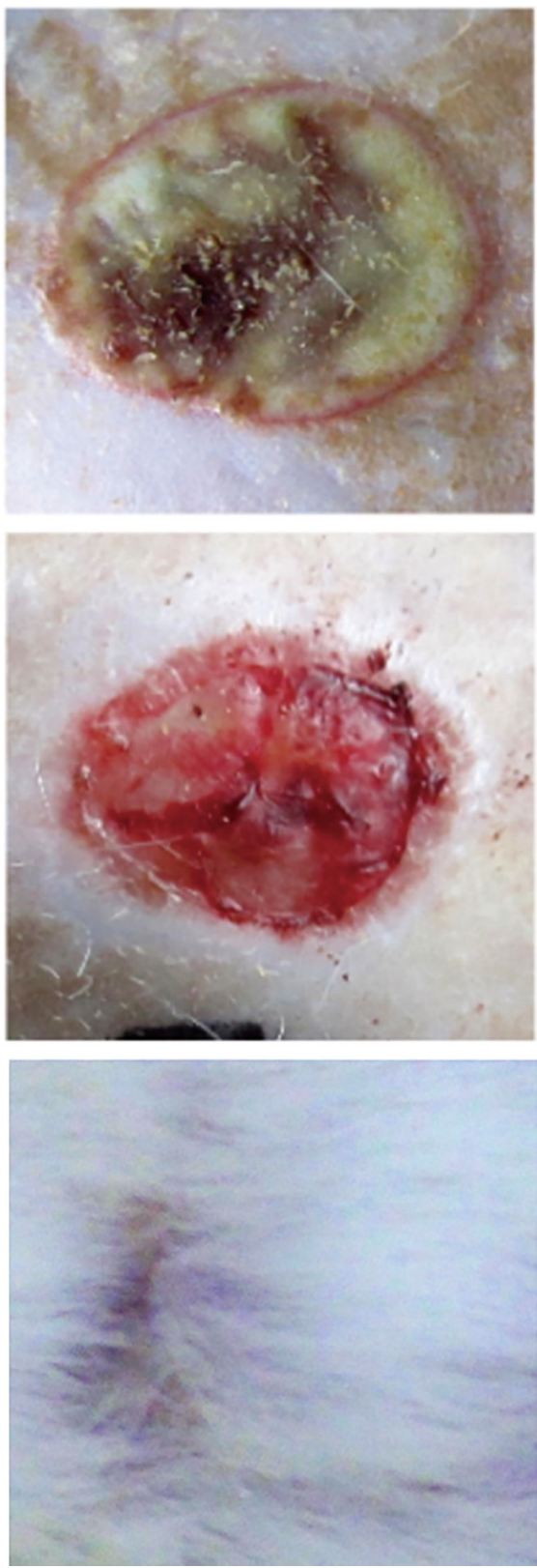

EE
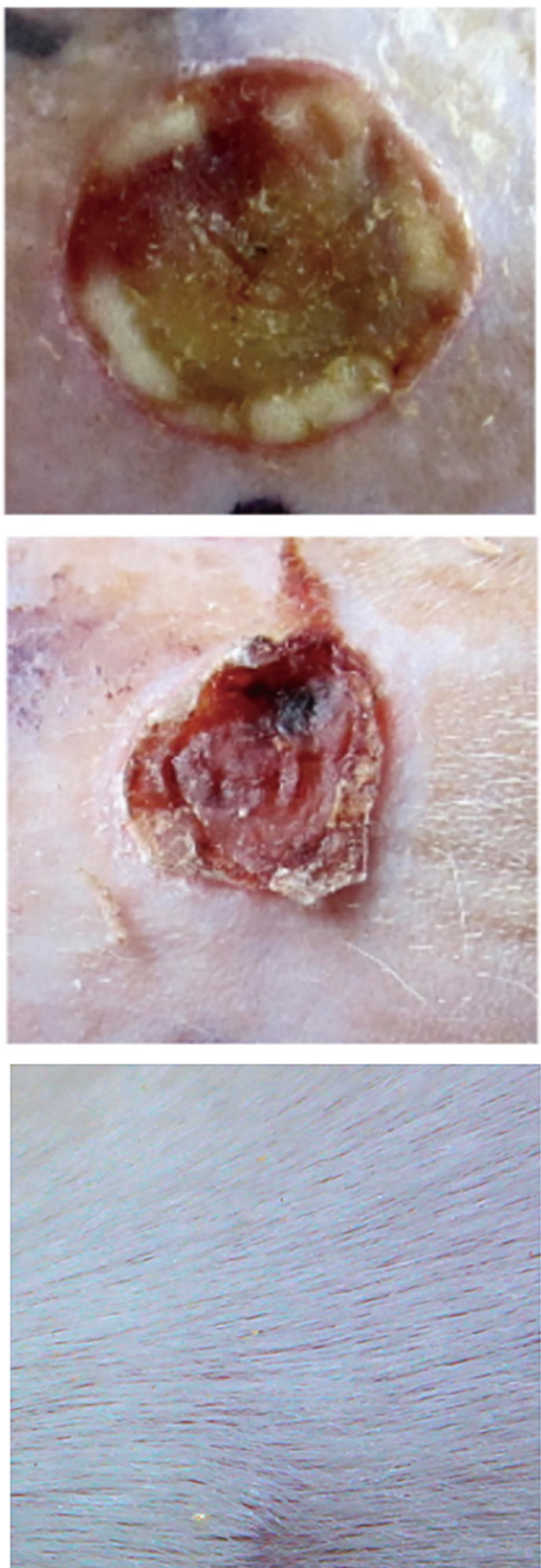

Figure 1 Macroscopic evaluation of wound at the different time points in each group.

\section{$W C$}

The WC in each group decreased during the wound healing process (Table 3). The $\mathrm{WC}$ in the $\mathrm{EE}$ and $\mathrm{JWH}$ groups was significantly lower than that in the control group at each time point $(\mathrm{P}<0.01)$. However, no significant difference in the WC between $\mathrm{EE}$ and JWH groups $(\mathrm{P}>0.05)$ was observed, indicating that $\mathrm{EE}$ and $\mathrm{JWH}$ were equally effective in reducing WC and relieving tissue edema after burn injury. 
Table 1 WHR and WHT of mice in each group (mean \pm SD, n=6/group/time point)

\begin{tabular}{|c|c|c|c|c|c|}
\hline Groups & \multicolumn{4}{|c|}{ WHR (\%) } & WHT (d) \\
\hline Control & $10.32 \pm 2.24$ & $51.42 \pm 4.09$ & $71.55 \pm 2.98$ & $94.86 \pm 1.89$ & $17.05 \pm 0.61$ \\
\hline JWH & $11.62 \pm 3.15$ & $61.45 \pm 2.28^{\star \star}$ & $84.68 \pm 4.66^{\star \star}$ & $100^{\star \star}$ & $14.05 \pm 0.68^{\star \star}$ \\
\hline EE & $12.34 \pm 2.97$ & $69.62 \pm 6.25^{\star \star^{++}}$ & $87.85 \pm 2.75^{\star \star^{++}}$ & $100^{\star \star}$ & $12.57 \pm 0.42^{\star \star^{+}}$ \\
\hline
\end{tabular}

WHR, wound healing rate; WHT, wound healing time; POD, postoperative day. ${ }^{*}, \mathrm{P}<0.05$ compared with the control group; ${ }^{* *}, \mathrm{P}<0.01$ compared with the control group; ${ }^{+}, \mathrm{P}<0.05$ compared with the JWH group; ${ }^{++}, \mathrm{P}<0.01$ compared with the JWH group.

\section{Hyp content}

The content of Hyp in skin wound in all the groups increased over time (Table 3). The Hyp content in the EE and $\mathrm{JWH}$ groups were significantly higher than the control group at every time point $(\mathrm{P}<0.01$, Table 4$)$. In addition, the EE group had higher Hyp content than JWH group at every time point $(\mathrm{P}>0.05)$.

\section{Hematology parameters}

All the groups showed a similar trend in PLT number. The PLT number increased swiftly during the first week, reached its peak at POD 7, and then began to fall after POD 11 (Table 4). More PLT in the EE and JWH groups than the control group at POD 3, 7, and $11(\mathrm{P}<0.01)$. The EE group had a higher PLT number than JWH group at POD 7 $(\mathrm{P}<0.05)$. However, at POD 15, there was no difference in PLT numbers among the three groups $(\mathrm{P}>0.05)$.

The WBC numbers in the EE and JWH groups stayed at a relatively high level and were significantly higher than the control group in the first week after injury $(\mathrm{P}<0.01$, Table 4). Furthermore, the number of $\mathrm{WBC}$ was higher in the EE group than JWH group at POD $3(\mathrm{P}<0.05)$. No difference was found among the three groups after POD 11 $(\mathrm{P}>0.05)$. WBC count in the control group increased in the initial 11 days, and since then would decrease back to the normal level.

The change of GRAN number in the three groups showed a similar trend: increasing, reaching its peak at $\mathrm{POH}$ 12, then decreasing (Table 4). Compared with the control group, the number of GRAN was significantly higher in the $\mathrm{EE}$ and $\mathrm{JWH}$ groups during the first $24 \mathrm{~h}(\mathrm{P}<0.01)$. The GRAN number in the EE group was higher than the JWH group from the $\mathrm{POH} 12(\mathrm{P}<0.01)$ to $\mathrm{POD} 1(\mathrm{P}<0.05)$ time period, indicating that $\mathrm{EE}$ was more effective than $\mathrm{JWH}$ in accelerating GRAN gathering and differentiation in blood after injury. However, there was no difference among the three groups at POD $3(\mathrm{P}>0.05)$.

\section{Discussion}

The basic physiological processes of skin wound healing are dynamic and complex, and are divided into inflammatory phase, proliferative phase, and remodeling phase, which involve inflammatory factors, such as interleukin (IL)-1, IL-6, tumor necrosis factor- $\alpha$ (TNF- $\alpha$ ), platelet derived growth factor (PDGF). These factors induce migration of inflammatory cells, fibroblasts, and keratinocytes to the wound site. Afterwards, these cells proliferate and differentiate, participate in re-epithelization, angiogenesis, deposition of new matrix, and finally restoring the normal function of the skin $(21,22)$. In the present study, mice skin burn wound model was treated with different modalities to evaluate their therapeutic effects. Our series of experiments found that EE had an obvious therapeutic effect in promoting burn wound healing.

At 11 days after burn injury, the WHR was as high as $87.85 \%$ after EE treatment, significantly higher than the JWH group. At this time point, the wound site in the control group was still covered with dense scabbing. This result indicated that $\mathrm{EE}$ was able to promote burn wound healing better than JWH.

The WC in normal skin is relatively constant. When an inflammatory reaction happens, the permeability of micro-circulation will increase, capillary expansion leads to exudation and tissue edema, causing a high WC in skin after burn wound formation. The prognosis of the microcirculation stasis determines the extent of the burn wound injury. If the micro-circulation was improved, it could effectively reduce thrombosis formation, relieve local tissue damage, and repair the wound (23). Therefore, reducing edema is vital during wound healing. We observed WC 
Control
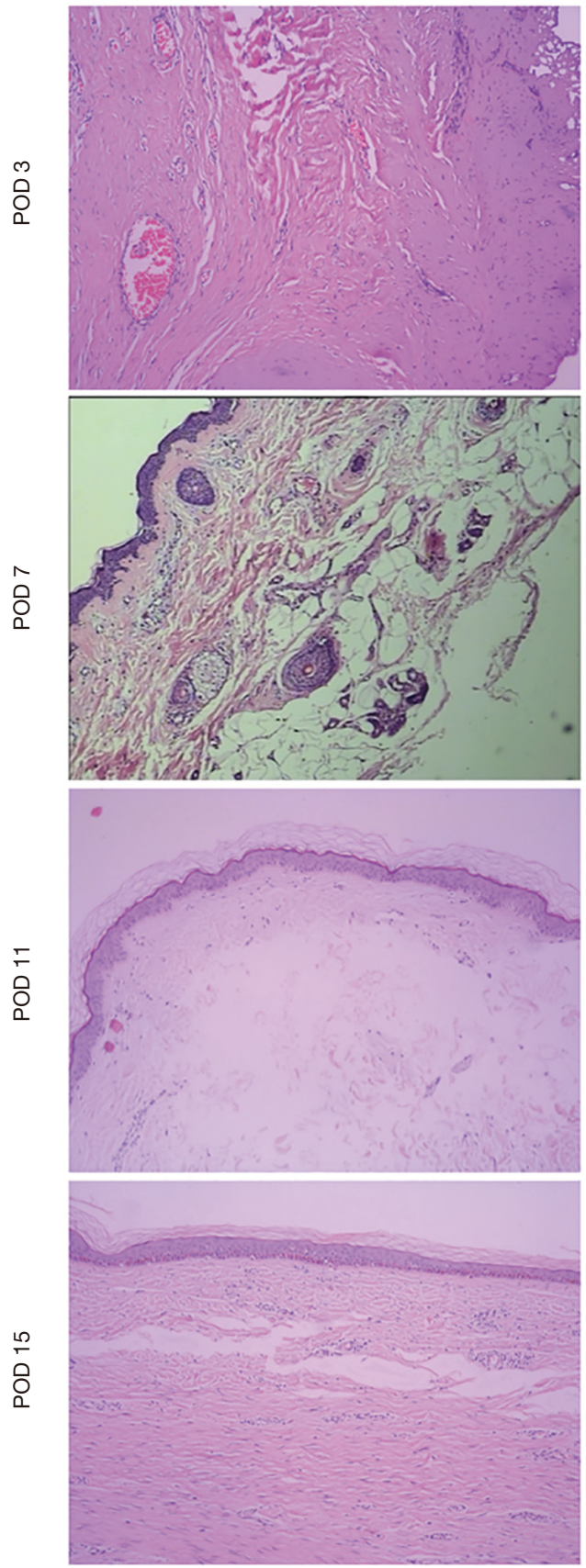

JWH
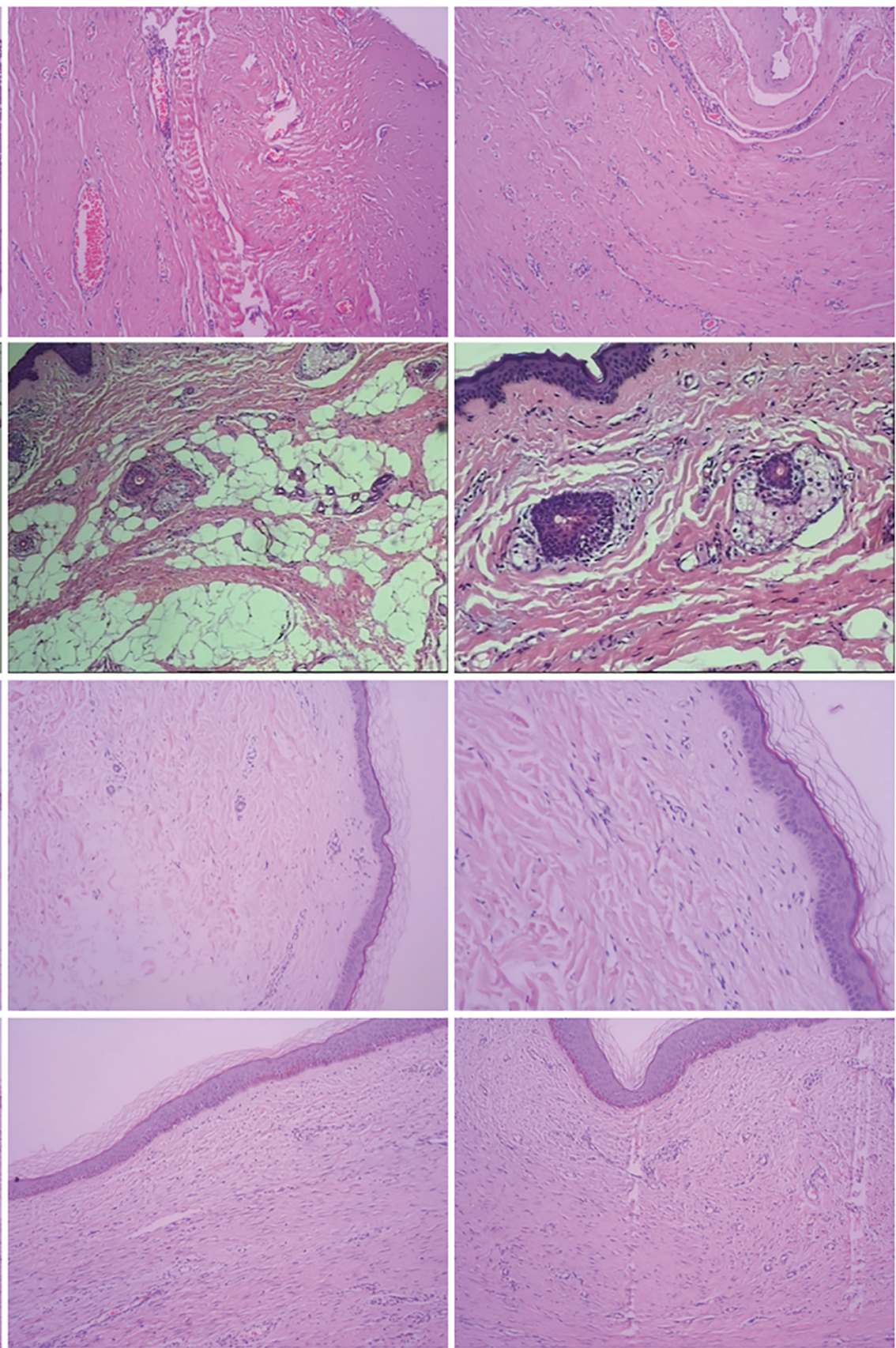

EE
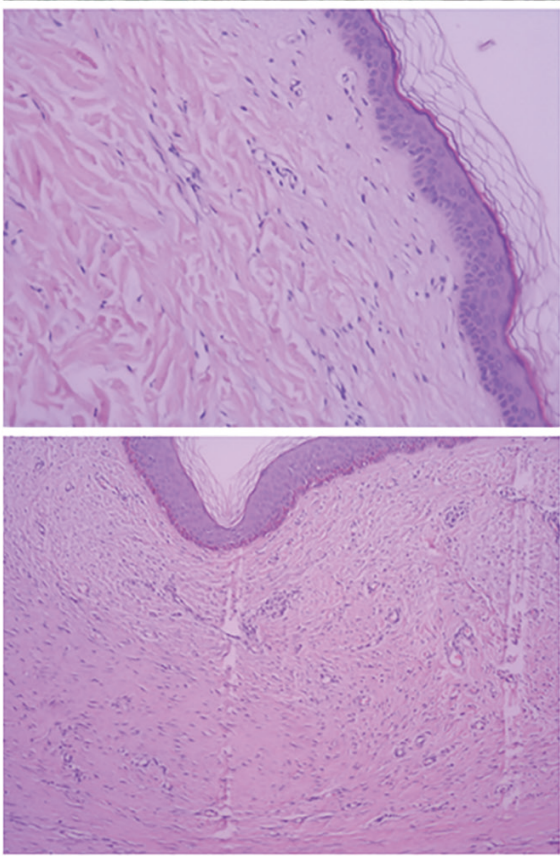

Figure 2 Histological characteristics of wound healing in each group at different time points after burn injury. (HE staining, magnification $\times 100)$.

decreasing over time in the three groups. However, the WC in the EE group was significantly lower than the control group, indicating that EE could effectively reduce local tissue edema and promote wound healing after burn damage.

The content of Hyp in skin is relatively stable and it can reflect its collagen content, which is beneficial to wound healing in all stages (24). The amount of collagen can be 
Table 2 Cell numbers of fibroblasts, fibrocytes, capillary endothelial cells, and epithelial cells at the wound site of mice in each group at POD 11 (mean $\pm \mathrm{SD}, \mathrm{n}=6$ /group/time point)

\begin{tabular}{llccc}
\hline Group & Fibroblasts & Fibrocytes & Capillary endothelial cells & Epithelial cells \\
\hline Control & $43.42 \pm 2.89$ & $9.42 \pm 2.42$ & $3.35 \pm 0.57$ & $1.76 \pm 0.84$ \\
JWH & $54.77 \pm 4.15^{\star *}$ & $29.32 \pm 1.28^{* *}$ & $4.04 \pm 0.38^{\star *}$ & $3.20 \pm 0.74^{* \star}$ \\
EE & $72.89 \pm 6.87^{* *^{++}}$ & $49.85 \pm 4.59^{* *^{++}}$ & $5.39 \pm 0.53^{\star *+}$ & $5.87 \pm 1.29^{\star * *}$ \\
\hline
\end{tabular}

${ }^{*}, \mathrm{P}<0.05$ compared with the control group; ${ }^{* *}, \mathrm{P}<0.01$ compared with the control group; ${ }^{+}, \mathrm{P}<0.05$ compared with the JWH group; ${ }^{++}$, $\mathrm{P}<0.01$ compared with the JWH group.

Table $3 \mathrm{WC}$ and Hyp content of the wound tissue in each group (mean $\pm \mathrm{SD}, \mathrm{n}=6$ /group/time point)

\begin{tabular}{|c|c|c|c|c|}
\hline Group & POD 3 & POD 7 & POD 11 & POD 15 \\
\hline Control & $73.2 \pm 3.1$ & $65.6 \pm 1.4$ & $62.8 \pm 2.8$ & $58.9 \pm 2.2$ \\
\hline JWH & $65.4 \pm 3.0^{\star \star}$ & $61.2 \pm 1.9^{\star \star}$ & $57.1 \pm 2.2^{\star *}$ & $51.4 \pm 1.3^{\star *}$ \\
\hline EE & $66.4 \pm 2.9^{\star *}$ & $60.9 \pm 1.5^{\star \star}$ & $56.8 \pm 2.6^{\star \star}$ & $50.7 \pm 2.1^{* *}$ \\
\hline Control & $2.18 \pm 0.17$ & $2.42 \pm 0.21$ & $3.19 \pm 0.23$ & $3.33 \pm 0.25$ \\
\hline JWH & $2.61 \pm 0.26^{\star \star}$ & $3.11 \pm 0.26^{\star \star}$ & $3.52 \pm 0.23^{\star *}$ & $3.90 \pm 0.23^{\star \star}$ \\
\hline EE & $2.91 \pm 0.22^{\star \star+}$ & $3.49 \pm 0.26^{\star \star+}$ & $3.78 \pm 0.26^{\star \star+}$ & $4.318 \pm 0.37^{\star \star+}$ \\
\hline
\end{tabular}

WC, water content; Hyp, hydroxyproline; POD, postoperative day. ${ }^{*}, \mathrm{P}<0.05$ compared with the control group; ${ }^{\star *}, \mathrm{P}<0.01$ compared with the control group; ${ }^{+}, \mathrm{P}<0.05$ compared with the JWH group; ${ }^{++}, \mathrm{P}<0.01$ compared with the JWH group.

Table 4 PLT, WBC, and GRAN numbers of mice in each group $\left(10^{9} / \mathrm{L}\right.$, mean $\pm \mathrm{SD}, \mathrm{n}=6 /$ group/time point $)$

\begin{tabular}{|c|c|c|c|c|}
\hline Group & POD 3 & POD 7 & POD 11 & POD 15 \\
\hline Control & $413 \pm 2.37$ & $429 \pm 6.74$ & $396 \pm 7.58$ & $367 \pm 24.23$ \\
\hline JWH & $446 \pm 5.47^{\star \star}$ & $476 \pm 8.27^{\star \star}$ & $428 \pm 5.72^{\star \star}$ & $369 \pm 29.89$ \\
\hline EE & $459 \pm 10.63^{\star *}$ & $513 \pm 18.67^{\star \star+}$ & $439 \pm 4.87^{\star \star}$ & $363 \pm 20.87$ \\
\hline Control & $9.29 \pm 0.21$ & $10.62 \pm 0.48$ & $11.14 \pm 0.41$ & $8.37 \pm 0.28$ \\
\hline JWH & $11.44 \pm 0.92^{\star \star}$ & $12.92 \pm 0.28^{\star \star}$ & $10.74 \pm 0.45$ & $8.47 \pm 0.48$ \\
\hline EE & $12.97 \pm 0.54^{\star \star+}$ & $12.12 \pm 0.13^{\star *}$ & $11.04 \pm 0.33$ & $8.56 \pm 0.12$ \\
\hline \multicolumn{5}{|l|}{ GRAN } \\
\hline EE & $225 \pm 11.24^{\star \star}$ & $329 \pm 24.85^{\star \star++}$ & $241 \pm 13.53^{\star \star+}$ & $13 \pm 3.24$ \\
\hline
\end{tabular}

PLT, platelet; WBC, white blood cell; GRAN, neutrophilic granulocyte; POD, postoperative day; $\mathrm{POH}$, postoperative hour. * $\mathrm{P}<0.05$ compared with the control group; ${ }^{* *}, \mathrm{P}<0.01$ compared with the control group; ${ }^{+}, \mathrm{P}<0.05$ compared with the $\mathrm{JWH}$ group; ${ }^{++}, \mathrm{P}<0.01$ compared with the JWH group. 
indirectly reflected via determining the Hyp content at the wound site. Skin wound repair starts with the formation of collagen. Meantime, it also contribute to scar formation (25). We found significantly higher Hyp content in the EE group than the other two groups, indicating an accelerated formation of collagen and extracellular matrix (ECM) to promote burn wound healing.

We detected larger amount of WBCs, GRANs, and PLTs in EE and JWH groups, which means EE was able to accelerate the proliferation of these cells in blood. In all the groups, the number of these blood cells showed the similar tend of change during wound healing: increased swiftly in the early stage, decreased at the later stages. Therefore, during the process of wound healing, EE plays the role to quick response to inflammatory reaction, stimulate blood cells proliferation and gathering, promote clot formation, as well as removal of the necrotic tissues. More PLT activation and gathering can greatly accelerate blood clot formation and muscularization.

The active ingredients in EE can promote blood circulation by removing blood stasis. They can relieve pain and other compression symptoms caused by edema surrounding the local tissue, provide enough blood supply to the nerve endings by improving microcirculation, as well as relaxing hair follicles and smooth muscle cells on the capillaries (26). EE solution helps keep the burn wound surface hydrated. It was found that the moist wound surface is an ideal environment that facilitates cell migration and maintenance of biological activities (27). Moreover, local application of EE barely irritates sensory nerve endings or causes other side effects $(28,29)$. EE is effective in stimulating granulation growth, reducing proliferation of hypertrophic scar, as well as demonstrating anti-oxidant activity. The active ingredients of EE include acetylcholinesterase, calmodulin, angiotensin, antioxidase, anti-bacterial peptide, plasmin, plasminogen activator, and so on (30). The ability of promoting burn wound healing is likely to be the joint effects of the aforementioned substances. Acetylcholinesterase and calmodulin together could relieve the pain response after burn $(31,32)$. The angiotensin and antioxidase systems can reduce the formation of inflammatory cytokines and finally stop the inflammatory cascade response. Removal of pathogens and toxins means the host is less likely to get toxaemia and create favorable conditions for tissue repair and regeneration $(33,34)$. Anti-bacterial peptide, plasmin and plasminogen activator reduce this risk of secondary infection after burn injury to a large extent (35). Consequently, EE could effectively promote burn wound healing, relieve pain, and reduce mortality rate.

One of the most serious outcomes after burn is scar formation. Though a scar is composed of the same protein (collagen) as its original tissue, the collagen fiber composition is totally different. Instead of a random basketweave formation of the collagen fibers observed in normal tissue, the collagen fibers cross-link and forms a remarkable alignment in a single direction in fibrosis (36). The scar tissue usually results in inferior function and quality. Skin with scarring is less sensitive to outside stimuli, less resistant to ultraviolet radiation, and hair follicles and sweat glands do not grow back within the scar tissue (37). Our study showed more fibroblasts and fibrocytes at the wound site during the healing process in the EE treatment group. The neonatal skin was smooth without scar formation on the surface. We also observed more capillary endothelial cells and epithelial cells gathering at the wound site, suggesting that EE could promote burn wound healing through angiogenesis and endothelium regeneration.

The limitations of the study should also be mentioned. We have not yet isolated the active molecular substances in EE that promote burn wound healing as well as the underlying modulation and signaling pathway mechanisms. In addition, the sample size of this research may still be insufficient, which will bias some research results. Grossly, any adverse effects of EE in this study have not been observed, but still need more long-term follow-up results to verify its harmlessness. Future studies will be launched to address these questions.

\section{Conclusions}

This study found that EE had an obvious therapeutic effect in promoting severe burn wound healing via decreasing edema, suppression of fibrosis, activation of angiogenesis and epithelial regeneration, inhibition of scar formation, and reduction of the risk of infection. Thus, EE could be used as a promising burn wound healing agent.

\section{Acknowledgments}

Funding: This study was supported by the National Natural Science Foundation of China $(81902303,81902682$, $81874030,82072506)$, the Natural Science Foundation of Hunan Province (2020JJ3060), Innovation-Driven Project of Central South University (No. 2020CX045), Jieping Wu Medical Foundation (320.6750.2020-03-14) 
and CMA-Young and Middle-aged Doctors Outstanding Development Program--Osteoporosis Specialized Scientific Research Fund Project (G-X-2019-1107-12), Guangdong Basic and Applied Basic Research Foundation (2020A151501048), Shenzhen Science and Technology Project (JCYJ20190806164216661), Hunan Administration of traditional Chinese Medicine (2021075) and Clinical Research Project of Shezhen Second People's Hospital (20203357028).

\section{Footnote}

Reporting Checklist: The authors have completed the ARRIVE reporting checklist. Available at http://dx.doi. org/10.21037/apm-20-2393

Data Sharing Statement: Available at http://dx.doi. org/10.21037/apm-20-2393

Conflicts of Interest: All authors have completed the ICMJE uniform disclosure form (available at http://dx.doi. org/10.21037/apm-20-2393). The authors have no conflicts of interest to declare.

Ethical Statement: The authors are accountable for all aspects of the work in ensuring that questions related to the accuracy or integrity of any part of the work are appropriately investigated and resolved. Experiments were performed under a project license (No.: 201907666) granted by the Ethics Committee of Xiangya Hospital, Central South University, in compliance with guidelines for the care and use of animals.

Open Access Statement: This is an Open Access article distributed in accordance with the Creative Commons Attribution-NonCommercial-NoDerivs 4.0 International License (CC BY-NC-ND 4.0), which permits the noncommercial replication and distribution of the article with the strict proviso that no changes or edits are made and the original work is properly cited (including links to both the formal publication through the relevant DOI and the license). See: https://creativecommons.org/licenses/by-nc-nd/4.0/.

\section{References}

1. Ottomann C, Stojadinovic A, Lavin PT, et al. Prospective randomized phase II Trial of accelerated reepithelialization of superficial second-degree burn wounds using extracorporeal shock wave therapy. Ann Surg 2012;25 5:23-9.

2. Taheri A, Mansoori P, Al-Dabagh A, et al. Are corticosteroids effective for prevention of scar formation after second-degree skin burn? J Dermatolog Treat 2014;25:360-2.

3. Kowal-Vern A, Gamelli RL, Walenga JM, et al. The effect of burn wound size on hemostasis: a correlation of the hemostatic changes to the clinical state. J Trauma 1992;33:50-6; discussion 6-7.

4. Rockwell WB, Ehrlich HP. Fibrinolysis inhibition in human burn blister fluid. J Burn Care Rehabil 1990;11:1-6.

5. Balamurugan M, Parthasarathi K, Ranganathan LS, et al. Hypothetical mode of action of earthworm extract with hepatoprotective and antioxidant properties. J Zhejiang Univ Sci B 2008;9:141-7.

6. Liu Z, Wang J, Zhang J, et al. An extract from the earthworm Eisenia fetida non-specifically inhibits the activity of influenza and adenoviruses. J Tradit Chin Med 2012;32:657-63.

7. Yang J, Wang T, Li Y, et al. Earthworm extract attenuates silica-induced pulmonary fibrosis through Nrf2-dependent mechanisms. Lab Invest 2016;96:1279-300.

8. Mihara H, Sumi H, Yoneta T, et al. A novel fibrinolytic enzyme extracted from the earthworm, Lumbricus rubellus. Jpn J Physiol 1991;41:461-72.

9. Jin L, Jin H, Zhang G, et al. Changes in coagulation and tissue plasminogen activator after the treatment of cerebral infarction with lumbrokinase. Clin Hemorheol Microcirc 2000;23:213-8.

10. Balamurugan M, Parthasarathi K, Cooper EL, et al. Earthworm paste (Lampito mauritii, Kinberg) alters inflammatory, oxidative, haematological and serum biochemical indices of inflamed rat. Eur Rev Med Pharmacol Sci 2007;11:77-90.

11. Balamurugan M, Parthasarathi K, Cooper EL, et al. Antiinflammatory and anti-pyretic activities of earthworm extract-Lampito mauritii (Kinberg). J Ethnopharmacol 2009;121:330-2.

12. Hattab S, Boughattas I, Boussetta H, et al. Transcriptional expression levels and biochemical markers of oxidative stress in the earthworm Eisenia andrei after exposure to 2,4-dichlorophenoxyacetic acid (2,4-D). Ecotoxicol Environ Saf 2015;122:76-82.

13. Prakash M, Balamurugan M, Parthasarathi K, et al. Antiulceral and anti-oxidative properties of "earthworm paste" of Lampito mauritii (Kinberg) on Rattus Norvegicus. Eur 
Rev Med Pharmacol Sci 2007;11:9-15.

14. Han CK, Kuo WW, Shen CY, et al. Dilong prevents the high-KCl cardioplegic solution administration-induced apoptosis in H9c2 cardiomyoblast cells mediated by MEK. Am J Chin Med 2014;42:1507-19.

15. Huang CY, Kuo WW, Liao HE, et al. Lumbrokinase attenuates side-stream-smoke-induced apoptosis and autophagy in young hamster hippocampus: correlated with eNOS induction and NFkappaB/iNOS/COX-2 signaling suppression. Chem Res Toxicol 2013;26:654-61.

16. Cooper EL, Ru B, Weng N. Earthworms: sources of antimicrobial and anticancer molecules. Adv Exp Med Biol 2004;546:359-89.

17. Deng ZH, Yin JJ, Luo W, et al. The effect of earthworm extract on promoting skin wound healing. Biosci Rep 2018;38:BSR20171366.

18. Luo W, Deng ZH, Li R, et al. Study of analgesic effect of earthworm extract. Biosci Rep 2018;38:BSR20171554.

19. Deng Z, Gao S, Xiao X, et al. The effect of earthworm extract on mice S180 tumor growth and apoptosis. Biomed Pharmacother 2019;115:108979.

20. Bunyapraphatsara N, Jirakulchaiwong $S$, Thirawarapan $\mathrm{S}$, et al. The efficacy of Aloe vera cream in the treatment of first, second and third degree burns in mice. Phytomedicine 1996;2:247-51.

21. Pang $\mathrm{Y}$, Wang D, Hu X, et al. Effect of volatile oil from Blumea Balsamifera (L.) DC. leaves on wound healing in mice. J Tradit Chin Med 2014;34:716-24.

22. Ghieh F, Jurjus R, Ibrahim A, et al. The Use of Stem Cells in Burn Wound Healing: A Review. Biomed Res Int 2015;2015:684084.

23. Papp A, Romppanen E, Lahtinen T, et al. Red blood cell and tissue water content in experimental thermal injury. Burns 2005;31:1003-6.

24. Gorres KL, Raines RT. Prolyl 4-hydroxylase. Crit Rev Biochem Mol Biol 2010;45:106-24.

25. Qiu L, Jin XQ, Xiang DL, et al. Study on the collagen constitution of hyperplastic scar in different ages and its influencing factors. Zhonghua Shao Shang Za Zhi 2003;19:236-40.

26. Zhang ZX, Wang FF. Effects of crude extract of

Cite this article as: He M, Xie WQ, Cheng G, Li WP, Yu DJ, Jin HF, Deng ZH, Li YS. The therapeutic effects of earthworm extract on deep second-degree burn wound healing. Ann Palliat Med 2021;10(3):2869-2879. doi: 10.21037/apm-20-2393 earthworm on promoting blood circulation to removing stasis. Zhongguo Zhong Xi Yi Jie He Za Zhi 1992;12:7413,10 .

27. Rippon MG, Ousey K, Cutting KF. Wound healing and hyper-hydration: a counterintuitive model. J Wound Care 2016;25:68, 70-5.

28. Zhang HL, Han R, Gu ZL, et al. A short-chain alphaneurotoxin from Naja naja atra produces potent cholinergic-dependent analgesia. Neurosci Bull 2006;22:103-9.

29. Chen ZX, Zhang HL, Gu ZL, et al. A long-form alphaneurotoxin from cobra venom produces potent opioidindependent analgesia. Acta Pharmacol Sin 2006;27:402-8.

30. Zhang M, Li X, Liu Y, et al. Effects of extract of dilong (pheretima) on the scalded skin in rats. J Tradit Chin Med 2006;26:68-71.

31. Hikida T, Kitabatake Y, Pastan I, et al. Acetylcholine enhancement in the nucleus accumbens prevents addictive behaviors of cocaine and morphine. Proc Natl Acad Sci U S A 2003;100:6169-73.

32. Zhou YQ, Liu DQ, Chen SP, et al. Cellular and Molecular Mechanisms of Calcium/Calmodulin-Dependent Protein Kinase II in Chronic Pain. J Pharmacol Exp Ther 2017;363:176-83.

33. Rodrigues Prestes TR, Rocha NP, Miranda AS, et al. The Anti-Inflammatory Potential of ACE2/Angiotensin-(1-7)/ Mas Receptor Axis: Evidence from Basic and Clinical Research. Curr Drug Targets 2017;18:1301-13.

34. Miesel R, Zuber M. Copper-dependent antioxidase defenses in inflammatory and autoimmune rheumatic diseases. Inflammation 1993;17:283-94.

35. Li Q, Ke F, Zhang W, et al. Plasmin plays an essential role in amplification of psoriasiform skin inflammation in mice. PLoS One 2011;6:e16483.

36. Roseborough IE, Grevious MA, Lee RC. Prevention and treatment of excessive dermal scarring. J Natl Med Assoc 2004;96:108-16.

37. Fu XB, Sun TZ, Li XK, et al. Morphological and distribution characteristics of sweat glands in hypertrophic scar and their possible effects on sweat gland regeneration. Chin Med J (Engl) 2005;118:186-91. 